\title{
Approaching the necessity of pediatric palliative care in Colombia: a challenge for the health system.
}

Susana Orrego ( $\nabla$ susiorrego@hotmail.com )

Universidad CES https://orcid.org/0000-0001-8501-701X

Karine Posada

Universidad CES

Silvia Librada

Universidad de Extremadura

Juliana Lopera

Universidad Pontificia Bolivariana

Research article

Keywords: Palliative care, Pediatrics, Population, Needs Assessment, Epidemiology, Health Care Quality, Access, Evaluation

Posted Date: July 22nd, 2020

DOl: https://doi.org/10.21203/rs.3.rs-41367/v1

License: (c) (i) This work is licensed under a Creative Commons Attribution 4.0 International License.

Read Full License 
Approaching the necessity of pediatric palliative care in Colombia: a challenge for the health system. A retrospective cross sectional study.

Authors: Orrego Susana ${ }^{1}$, Posada Karine ${ }^{1}$, Librada Silvia ${ }^{2}$, Lopera Juliana ${ }^{1}$

${ }^{1}$ Seguros SURA, Medellín. Colombia

${ }^{2}$ New Health Foundation. Sevilla. España

Corresponding autor: Susana Orrego sorregov@ sura.com.co 


\begin{abstract}
:
Background: Pediatric Palliative Care (PPC) focuses on achieving quality of life and control the symptoms for children during the sickness process, also provide support to the family in order to relief suffering and give response to needs assessment. In Colombia, this subspecialty does not exist, as a result of not having clinic practice guides and information about the population who benefit under 18 years of age. This study is to approach the necessity of PPC in our country, defining a methodology to characterize and estimate prevalence of pediatric population who may need special care in order to develop an attention model. Methods: A retrospective descriptive study was conducted among 80,926 members between 0 and 18 years of age who has a private health insurance in Colombia between January 1, 2016 and December 31, 2018. Data was obtained from the insurance transactional database. Patients were grouped based on the Association for children with life threatening conditions and their families (ACT) of the Royal College of Pediatrics four classifications plus perinatal group. Results were processed and analyzed using descriptive statistical functions in Microsoft Excel. Results: 1,694 patients (2,09\%) were eligible to enter a PPC program according to their IDC-10 diagnoses based on ACT plus group 5 classification. Approximately $54 \%$ were male, $57.97 \%$ were considered early childhood, $26.56 \%$ childhood and $15,47 \%$ adolescence. With regards to ACT classification and group 5; 55.55\% of patients had diagnosis from group 5 (55.55\%) followed by group 4 (23.2\%) and group 1 non-cancer $(9.68 \%)$. Being able to identify patients in need of PPC programs early may increase it being utilize at the time of diagnosis and not wait till the end of life. This might also help alleviate misconception of PPC only being offered during the end of life period. This study should help with the development of public and private politics aimed to promote the creation of PPC programs in developing countries.
\end{abstract}

Keywords: "Palliative care", "Pediatrics", "Population", "Needs Assessment", "Epidemiology", "Health Care Quality, Access, and Evaluation" 


\section{Declarations:}

This study was classified as an investigation with minimum risk according to the Colombian Ministry of Health resolution 8430 of 1993 article 11. This was an analysis of a secondary data. Personal data protection policy of the insurance company was apply.

Authors declared not having any conflict of interest about the study. A private insurance company from Colombia sponsored study. 


\section{Background}

World Health Organization (WHO) defined Pediatric Palliative Care (PPC) in 1998 as the total and active care of the body, mind and spirit of a child with a disease that threatens and/or limits his/her life. ${ }^{1}$ This care is focused on patients and their family by providing support in order to relief suffering and improve quality of life in both. PPC must be implemented from diagnosis and continue along the disease's trajectory independently of its outcome, and extended beyond the child's death to include the mourning process ${ }^{2}$. WHO estimates that 21,6 million children benefit from PPC, however, receipt of PPC is not uniform, being influenced by development, infrastructure and complexity of sanitary services of a country ${ }^{1}$ Children and adolescents who may benefit from palliative care is 15 per 10,000 inhabitants as of $2007^{3}$ The development of PPC has emerged due to focus on improving the needs of children with complex chronic and life threatening diseases through an integrated multidisciplinary team (pediatricians, nurses, social workers, psychologists, counselors etc) which ideally includes a pediatrician specialized in palliative care, a certified nurse, a social worker, a psychologist and a spiritual counselor trained in palliative care to offer a coordinated attention focused on the multidimensional care that these patients and their families require ${ }^{4}$.

PPC must be early referral from the diagnosis moment and continue along the disease's trajectory independently of its outcome, being extended beyond the child's death and assisting the mourning process ${ }^{2}$.

Association for children with life threatening conditions and their families (ACT) ${ }^{5}$ of the Royal College of Pediatrics and Children's Health in the United Kingdom (RCPCH) developed a classification that categorizes life-limiting and life- threatening conditions of children in 4 groups which may require PPC. Group 1 deals with conditions where treatment is feasible but may fail such as childhood cancer. Group 2 entails conditions which require prolonged treatments to improve quality of life but would be fatal if treatment is aborted such as cystic fibrosis. Group 3 involves progressive conditions where treatment is unavailable and therefore palliative care are the only option such as spinal muscular atrophy. Group 4 includes non-progressive irreversible severe neurological compromise which leads to high necessity of care and complications make them susceptible to premature death. 
Additionally, a fifth group has been developed due to an increase of premature births and consequently increase in prenatal, neonatal and perinatal affections. Group 5 entails patients that require special care in their first months of life due to perinatal or neonatal diagnosis and make them susceptible to continuous care and follow-up such as low birth weight and prematurity.

National legislation 1733 on palliative care ${ }^{6}$ was created in Colombia in September 2014. The Palliative care national clinic practice guide ${ }^{7}$ was published and socialized in 2016 excluding population under 18 years of age, resulting in PPC not being included. This is concerning considering that the National Administrative Department of Statistics (Departamento Administrativo Nacional de Estadística - DANE) estimated national childhood mortality was 16,80 deaths/1000 for children under one year of age in 2016 (Series 2005-2016) ${ }^{8}$. An analysis of 2018 Colombia's health situation revealed that between 2005 and 2017, an average of 8,625 childhood deaths and 5,494 neonatal deaths yearly were registered. Affections occurring in perinatal period generated nearly $50 \%$ of the mortality in under one-year-old. Secondly, the report stated that congenital malformations, deformities and chromosomic anomalies caused nearly $23 \%$, respiratory diseases caused about $8 \%$, and infectious and parasitic diseases caused 5\% of deaths.

Colombia does not have enough Palliative Pediatricians as a result of not having a palliative care subspecialty in medical schools, and obstacles faced with board certification by the National Ministry of Education. Seguros SURA is a private insurance company in Colombia with 365,000 members, of which 81,000 are under 18 years. Prevalence of diseases that will require PPC among individuals $<18$ years are unknown. The objective of this study was to define a methodology to estimate the prevalence of the pediatric population who may need PPC and to characterize this population in order to develop a PPC attention model. 


\section{Methods}

\section{Study design and population}

A descriptive study was conducted among individuals between 0 and 18 years of age who has a private health insurance in Colombia between January 1, 2016 and December 31, 2018.

\section{Sampling and variables}

The study population was obtained from the insurance transactional database. The insurance company's databases have a periodic quality audit process in order to guarantee that the final entered information is reliable. Patients were identified using the International Classification of Diseases, Tenth Revision, (ICD-10) codes. Patients were grouped based on the $\mathrm{ACT}^{5}$ of the Royal College of Pediatrics four classifications plus perinatal group 5. ICD-10 codes corresponding to benign tumors and tumors in adjacent locations $(n=196)$ that did not affect the quality of life of the patients were excluded. The IDC-10 diagnoses included and excluded in each ACT groups are presented in table 1. Sociodemographic variables (age, gender, and region) were included. The geographical region of origin was defined according to the regional office where the health policy was subscribed.

\section{Data Analysis}

Prevalence of diagnoses was stratified by age groups following the healthcare integrated routs (Rutas Integradas de Atención en Salud in Spanish, "RIAS") classification of pediatric population ${ }^{10}$, which categorizes as "early childhood" ages between 7 days and 5 years, "childhood" ages between 6 and 11 years, and adolescence between 12 and 18 years of age. The frequency of diagnoses in each ACT group plus group 5 were analyzed. Diagnoses with frequencies of two or less were combine and categorized as "others". Distribution by diagnosed related group according to the type of pathology and affected system was also reported. Results were processed and analyzed in Microsoft Excel. 


\section{Ethical considerations}

This study was classified as an investigation with minimum risk according to the Colombian Ministry of Health resolution 8430 of 1993 article 11. This was an analysis of a secondary data. Confidentiality of patients was protected, following the personal data protection policy of the insurance company. Only information that will help improve the risk assessment models of the covered population were obtained. 


\section{Results}

Between January 2016 and December 2018, 80,926 members under 18 years of age were insured by the insurance company. Of these, 1,694 patients $(2,09 \%)$ were eligible to enter a PPC program according to their IDC-10 diagnoses based on ACT plus group 5 classification. Approximately 54\% were male, $57.97 \%$ were considered early childhood, $26.56 \%$ childhood and 15,47\% adolescence (Table 2). Most of the participants resided in the Antioquia region $(56.85 \%)$, followed by Center $(17.89 \%)$, North (13.99\%) and West (11.28\%). With regards to ACT classification and group 5; the highest number of patients fell under group 5 (55.55\%) followed by group 4 (23.2\%) and group 1 non-cancer $(9.68 \%)$.

Early childhood patients were more prevalent within group 5. Adolescents were in the first place of prevalence in group 1 Oncological, and the second place was for group 4 with an $8.91 \%$ (Fig 1).

Figure 1. Distribution of diagnoses by age group and ACT group classifications plus group 5. Seguros Sura Insurance Company, Colombia 2016-2018.

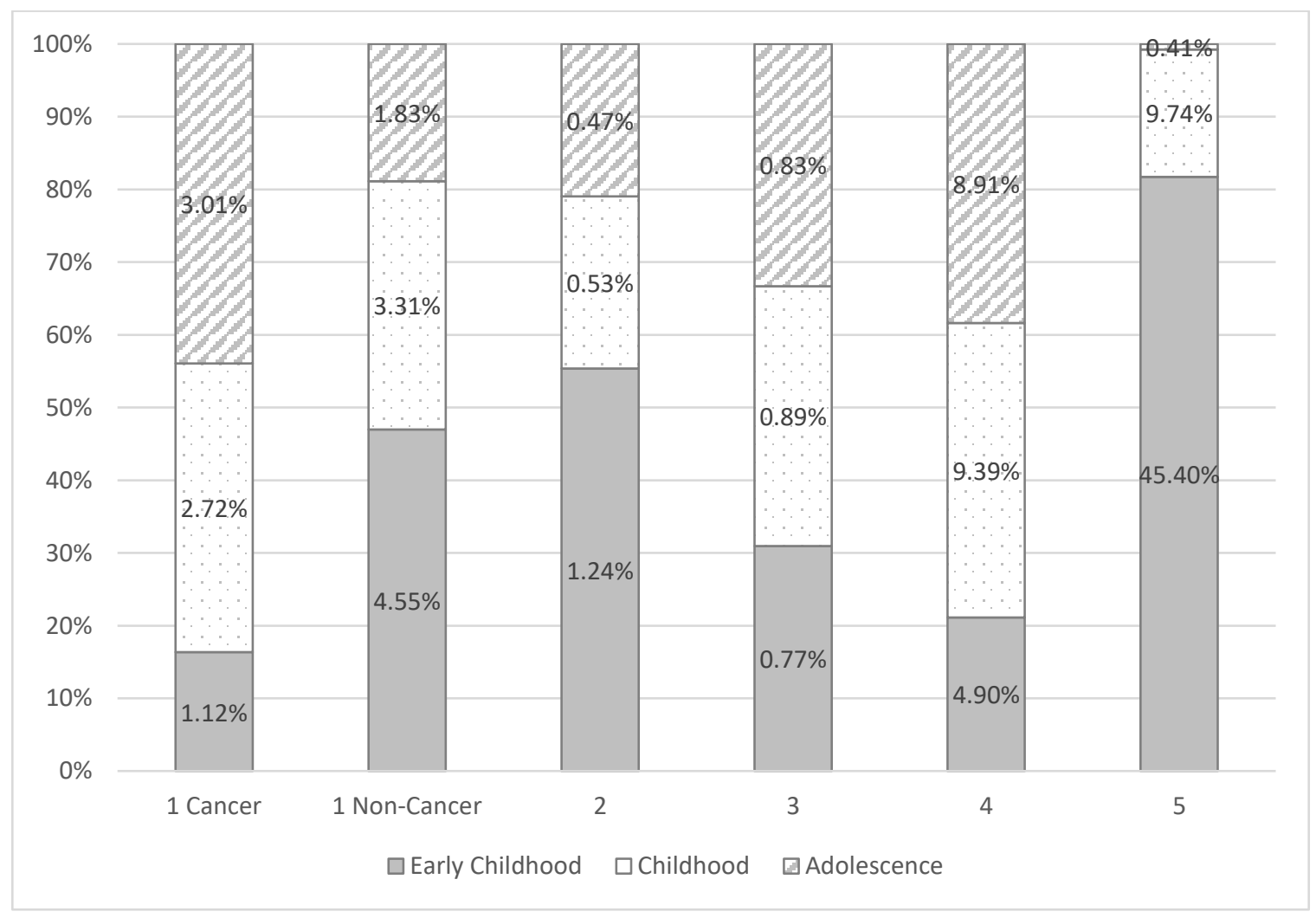


The most frequent diagnosis in the study population was "others preterm newborn" found in 767 children (45.28\%), followed by Epilepsy found in 284 (16.77\%), low birth weight in 62 (3.66\%) and Hematopoietic cancer in 47 patients (2.77\%) [Table 3]. Table 4 presents the list of diagnoses that fell under each ACT and group 5 classification. In group 1 - cancer; the most prevalent condition diagnosed was Hematopoietic CA (40,52\%) followed by Malignant Tumors in the NCS (12.93\%). In group 1 - non- cancer; Patent Ductus Arteriosus (17.07\%) was the most diagnosed condition followed by Atrial Septum defect (14.63\%) and Cardiac Congenital Malformation (14.02\%). The most diagnosed condition in group 2 was specified neuromuscular diseases (28.95\%), in group 3 was Myoclonus (26.19\%), in group 4 was Epilepsies $(72.26 \%)$, and in group 5 was other preterm newborns $(81,515)$.

\section{Discussion}

To our knowledge, this is the first study the implementation of ACT criteria and IDC-10 diagnoses that are associated with life-limiting and life-threatening conditions in the general pediatric population in Colombia. The findings from this study will allow the identification of children who are eligible for PPC, which aims to individualize health necessities in accordance to its level of risk.

We determine the prevalence of children in need of PPC to be $2.09 \%$ out of a total of 80,926 members under 18 years of age. Tirado and Zarate ${ }^{11}$ reported that in a population of 2,718 patients hospitalized during 3 years (2013-2015), 4.5\% were candidates for PPC. Bernadá et $\mathrm{al}^{12}$ found a prevalence of $3.3 \%$ among a population of 1,447 patients. Even though, the prevalence from our study is similar to these studies where patients were hospitalized, there is no national prevalence estimate that includes people outside the hospital environment. Regarding age, we found that $58 \%$ of diagnosed cases involved those considered early childhood which is consistent with Elorza et $\mathrm{al}^{13}$ who found a $52 \%$ cases in early childhood too. It should be noted that their population was hospitalized patients.

We found that group 5 had the highest proportion of patients at $55,55 \%$ and preterm newborns and low birth weight were the most prevalent diagnoses representing $81.51 \%$ and the $6.59 \%$ respectively in group 5 . Bernadá et $\mathrm{al}^{12}$ found group 5 to have the second highest proportion of patients. 
Group $4(23,20 \%)$ had the second highest proportion of patients with Epilepsies being the most prevalent diagnoses with $72.26 \%$ of the cases. This is also similar with Bernadá et al ${ }^{12}$ (34\%) but lower than Tirado and Zarate ${ }^{11}$ finding where group 4 was the most prevalent representing $44 \%$ of the study population. The third most prevalent group in our study was group 1 with a $16.53 \%$ (9.68\% for non-cancer and 6,85\% for cancer) of the study population. The most prevalent diagnoses in the cancer group were: Hematopoietic cancer (6.85\%), followed by CNS and Ocular Tumors, all three represented 62.93\% of their group. Other studies show that between 20 and 30\% of the patients fell under this group. Among 3,226 children, Elorza et al ${ }^{13}$ found $20.6 \%$ to be in this group and Tirado and Zarate ${ }^{12}$ found $14 \%$ among 2,718 hospitalized patients. The most prevalent diagnoses in the non-cancer group were patent Ductus Arteriosus (17.07\%), Atrial Septum defect (14.63\%) and Cardiac Congenital Malformation (14.02\%) which were similar to the ones Tirado and Zarate ${ }^{12}$ reported: Cardiac Congenital Malformations (70\%), Cardiac insufficiencies (21\%) and Cardiopathies (9\%).

Finally, group 2 was the least represented with a 2,24\% which is consistent with findings by Tirado and Zarate ${ }^{12}$ in which both groups $\mathbf{2}$ and $\mathbf{3}$ represented 3.3\%.

Were found that diagnoses that require PPC by ACT group and group 5 were heterogeneous and thus, additional studies are required in order to observe the tendency by age groups and by type of disease. Talking about prevalence of the PC susceptible population together with outlining the importance of setting in motion a PPC program constitutes a step forward towards the strengthening of these initiatives. Marvicsin et al ${ }^{14}$ performed a qualitative study about 9 PPC programs and they recommended beginning palliative care at diagnosis (which only happened in 5\% of the cases). These findings highlight the importance of referring patients to PPC programs at the time of diagnosis in order to improve the quality of life of both patients and their family. Previous studies have recommendations on the derivation processes $^{15,16}$ but more investigations are needed based on the real situation such as what this study investigated.

It is a national challenge to create a PPC program because it has not been widely implemented around the world and the misconception that PPC are needed only at the end of life. In Pediatrics, the program must be developed in children with acute and chronic pathologies 
without classifying them according to the probability index of dying within the next year. The proper derivation and development of PPC programs will have positive impact on patients, relatives and healthcare organizations due to reduced hospital admittance and unnecessary emergency visits. Comparative studies in this respect will be important once PPC programs are up and running.

\section{Limitations}

No other characteristics in the intervention levels such as variety of diagnosis of unpredictable duration, rare diseases, etc. were contemplated in this study. A group of characteristics to have in mind like specific medication availability, maturity aspects of the population which affect communication, education and support, the role of the family, the social, emotional and communitarian impact and the handling of grief were considered. The scarcity of studies on samples of patients susceptible of PPC and the implementation of these criteria has also been a limitation when comparing prevalence because despite contrasting some populations with the ACT groups, the variability in the inclusion of diagnoses of each group has not been identified. Therefore, it is adequate to identify the pathologies in each subgroup which may allow other organizations and teams to replicate this study in search of properly characterizing their susceptible population.

\section{Conclusions}

ACT classification and a fifth group were used to identify patients who are in need of PPC and examined the groups by various age groups. Being able to identify patients in need of PPC programs early may increase it being utilize at the time of diagnosis and not wait till the end of life. This might also help alleviate misconception of PPC only being offered during the end of life period. This study should help with the development of public and private politics aimed to promote the creation of PPC programs and the formation of professionals in PPC. Developing research that allows an early identification, early derivation, continuous follow up and integral treatment of the population and their relatives during the disease, death and mourning processes in this line is needed. 


\section{Abbreviations}

PC: Palliative Care

PPC: Pediatric Palliative Care

ACT: Association for children with life threatening conditions and their families (ACT)

IDC-10: International Classification of Diseases version 10

WHO: World Health Organization (WHO)

RIAS: Rutas Integradas de Atención en Salud

\section{References}

\footnotetext{
${ }^{1}$ World Health Organization. Integrating palliative care and symptom relief into paediatrics: a WHO guide for health-care planners, implementers and managers. World Health Organization. License: CC BY-NC-SA 3.0. ISBN 9789241514453.

${ }^{2}$ American Academy of Pediatrics. Committee on Bioethics and Committee on Hospital Care. Palliative Care for Children. Pediatrics 2000; 106(2): 351-7.

${ }^{3}$ Cochrane H, Liyanage S, Nantambi R. Palliative Care Statistics for Children and Young Adults. Health and Care Partnerships Analysis. Londres: Department of Health. 2007 Mayo;1-68.

${ }^{4}$ Ministerio De Sanidad, Servicios Sociales e Igualdad. Cuidados Paliativos pediátricos en el Sistema Nacional de Salud: Criterios de Atención. Madrid 2014.

${ }^{5}$ Association for Children with Life-Threatening or Terminal Conditions and their Families (ACT). Royal College of Paediatrics and Child Health. A guide to the development of children's palliative care services. London: Royal College of Paediatrics and Child Health 2003.

${ }^{6}$ Ley Consuelo Devis Saavedra. Ley 1733 DE 2014. Diario Oficial No. 49.268 de 8 de septiembre de 2014.

${ }^{7}$ Ministerio de Salud y protección Social. Instituto de Evaluación Tecnológica en Salud. Guía de Práctica Clínica para la atención de pacientes en Cuidado Paliativo (adopción). Sistema General de Seguridad Social en Salud. Colombia 2016.

${ }^{8}$ DANE. Estadísticas vitales nacimientos y defunciones. [cited 2020 march 20]. Available from: https://www.dane.gov.co/index.php/estadisticas-por-tema/demografia-y-poblacion/nacimientos-ydefunciones

${ }^{9}$ Análisis de situación de salud. Colombia 2018. https://www.minsalud.gov.co/sites/rid/Lists/BibliotecaDigital/RIDE/VS/ED/PSP/asis-colombia-2018.pdf

${ }^{10}$ Ministerio de Salud. Rutas Integrales de Atención en Salud - RIAS. [cited 2020 feb 12]. Available from: https://www.minsalud.gov.co/sites/rid/Lists/BibliotecaDigital/RIDE/DE/05-rias-presentacion.pdf

${ }^{11}$ Tirado I, Zarate A. Application of the Association for Children's Palliative Care (ACT) criteria at a pediatric reference institution in the Colombian Caribbean. Rev. Salud Pública 2018; 20(3): 378-383.

12 Bernadá M, Parada M, Dallórso P, Stewart J, García A. Niños egresados del Hospital Británico con condiciones de salud pasible de Cuidados Paliativos. Estudio epidemiológico. Arch Pediatr Urug 2012; 86(1): 6-13.

${ }^{13}$ Elorza M, García A, Vanegas C, Fernández M. Características epidemiológicas, clínicas y evolutivas de los pacientes pediátricos con enfermedades crónicas y limitantes. Susceptibles de recibir atención por cuidados paliativos en el Hospital Pablo Tobón Uribe, Medellín, Colombia. Medicina U.P.B 2018;37(2): 116-124.
} 
${ }^{14}$ Marvicsin D, Bonner C, Jean L. Pediatric Palliative Care: Identification of the Referral Process and Collaboration of the Pediatric Palliative Care Team and the Primary Care Provider. J Palliative Care Med 2012; 2: 111.

${ }^{15}$ Friebert S, Osenga K. Pediatric Palliative Care Referral Criteria. Center to Advance Palliative Care. 2009.

${ }^{16}$ Kaye EC, Friebert S, Baker JN. Early Integration of Palliative Care for Children with High-Risk Cancer and Their Families. Pediatr Blood Cancer 2016;63(4): 593-597.

\section{Tables}

Table 1. IDC-10 code classification of diagnoses according to ACT grouping plus group 5.

\begin{tabular}{|c|c|c|}
\hline ACT Group & Number of IDC-10 associated diagnoses & IDC -10 codes \\
\hline 1 Cancer & 778 & C00-C97X - D00X -D48X - C910 \\
\hline 1Non Cancer & 95 & $\begin{array}{l}\text { I11 - } 13 \text { X I27X - Q20 - Q28X - K72X - } \\
\text { N18X - N19X }\end{array}$ \\
\hline 2 & 70 & $\begin{array}{l}\mathrm{B} 20 \mathrm{X} \text { - B24X - Q41X-Q42X - Q61X- Q780 } \\
\text { - Q81X - E84X - G71X }\end{array}$ \\
\hline 3 & 102 & $\begin{array}{l}\text { G12X - G13X - G23X - G24X - G26X - } \\
\text { G31X - G32X -G35X - G36X - G378 -G379 } \\
\text { - G40X - E760 - G4X - A811 -A812 - G23X } \\
\text { - G30X - F842 - G118 - G119 }\end{array}$ \\
\hline 4 & 76 & $\begin{array}{l}\text { B941 - G80X - G81X -G82X -G83X - } \\
\text { G90X - G91X - G92X - G94X - G95X - } \\
\text { G98X - G99X - I69X - P57X }\end{array}$ \\
\hline 5 & 56 & $\begin{array}{l}\text { P07X -P11X - P20X -P21X -P52X -P91X - } \\
\text { P94X- Q00X -Q04X- Q91X }\end{array}$ \\
\hline Excluded & 196 & $\begin{array}{l}\text { D24X - D251 - D370 - D38X - D391 - D40X } \\
\text { - R190 }\end{array}$ \\
\hline
\end{tabular}


Table 2. Distribution of study population. Seguros Sura Insurance Company, Colombia 2016-2018.

\begin{tabular}{|l|r|r|}
\hline Characteristic & \multicolumn{1}{|c|}{ 莎 } & \\
\hline Gender & 784 & 46.28 \\
\hline Female & 910 & 53.72 \\
\hline Male & & \\
\hline Age Group & 982 & 57.97 \\
\hline Early Childhood & 450 & 26.56 \\
\hline Childhood & 262 & 15.47 \\
\hline Adolescence & & \\
\hline Region & 963 & 56.85 \\
\hline Antioquia & 303 & 17.89 \\
\hline Center & 237 & 13.99 \\
\hline North & 191 & 11.28 \\
\hline West & & \\
\hline ACT Classification & 116 & 6.85 \\
\hline 1 Cancer & 164 & 9.68 \\
\hline 1 Non-Cancer & 38 & 2.24 \\
\hline 2 & 42 & 2.48 \\
\hline 3 & 393 & 23.20 \\
\hline 4 & 941 & 55.55 \\
\hline 5 & & \\
\hline
\end{tabular}

Table 3. Distribution of diagnoses in the study population. Seguros Sura Insurance Company, Colombia 2016-2018. ( $\mathrm{N}=1,694)$.

\begin{tabular}{|l|r|r|}
\hline Diagnoses & $\mathbf{n}$ & $\mathbf{\%}$ \\
\hline Others newborn preterm & 767 & $45.28 \%$ \\
\hline Epilepsies & 284 & $16.77 \%$ \\
\hline Other Low Birth weight & 62 & $3.66 \%$ \\
\hline Hematopoietic CA & 47 & $2.77 \%$ \\
\hline Patent Ductus Arteriosus & 28 & $1.65 \%$ \\
\hline Quadriplegic Spastic cerebral palsy & 27 & $1.59 \%$ \\
\hline Atrial Septum defect & 24 & $1.42 \%$ \\
\hline Neonatal Brain depression & 24 & $1.42 \%$ \\
\hline Congenital Cardiac Malformation & 23 & $1.36 \%$ \\
\hline
\end{tabular}




\begin{tabular}{|l|r|r|}
\hline Asphyxiation of birth & 22 & $1.30 \%$ \\
\hline Primary Pulmonary Hypertension & 21 & $1.24 \%$ \\
\hline Congenital Hypotonia & 18 & $1.06 \%$ \\
\hline Extreme Immaturity & 17 & $1.00 \%$ \\
\hline CNS Malignant Tumors & 15 & $0.89 \%$ \\
\hline Hydrocephalus & 13 & $0.77 \%$ \\
\hline Family Dysautonomia [Riley-Day Syndrome] & 13 & $0.77 \%$ \\
\hline Malignant Ocular/eye Tumor & 11 & $0.65 \%$ \\
\hline Ventricular Septum defect & 11 & $0.65 \%$ \\
\hline Specified neuromuscular disorders & 11 & $0.65 \%$ \\
\hline Myoclonus & 11 & $0.65 \%$ \\
\hline
\end{tabular}

Table 4. Distribution of diagnoses by age group and ACT group classification plus group 5. Seguros Sura Insurance Company, Colombia 2016-2018.

\begin{tabular}{|l|l|r|r|}
\hline Group & Diagnoses & N & \% \\
\hline \multirow{1}{*}{ Cancer } & Hematopoietic CA & 47 & 40.52 \\
\hline & Malignant Tumors in the NCS & 15 & 12.93 \\
\hline & Malignant Ocular/eye Tumor & 11 & 9.48 \\
\hline & Bone Malignant Tumors & 8 & 6.90 \\
\hline & Malignant Tumor of the Retroperitoneum & 8 & 6.90 \\
\hline & Melanoma & 5 & 4.31 \\
\hline & Thyroid Malignant Tumor & 5 & 4.31 \\
\hline & Liver Malignant Tumors & 4 & 3.45 \\
\hline & Oral Cavity Malignant Tumor & 5 & 4.31 \\
\hline & Respiratory System Malignant Tumor & 3 & 2.58 \\
\hline & Ovary Malignant Tumor & 2 & 1.72 \\
\hline & Others group 1 Oncological & 3 & 2.59 \\
\hline \multirow{3}{*}{ Non-Cancer } & Patent Ductus Arteriosus & 28 & 17.07 \\
\hline & Atrial Septum defect & 24 & 14.63 \\
\hline & Cardiac Congenital Malformation & 23 & 14.02 \\
\hline & Primary Pulmonary Hypertension & 21 & 12.80 \\
\hline & Ventricular Septum defect & 11 & 6.71 \\
\hline & Coarctation of the aorta & 10 & 6.10 \\
\hline & Arteriovenous Malformation of cerebral vessels & 5 & 3.05 \\
\hline
\end{tabular}




\begin{tabular}{|c|c|c|c|}
\hline & Peripheral Arteriovenous Malformation & 4 & 2.44 \\
\hline & Non specified chronic Kidney disease & 5 & 3.05 \\
\hline & Fallot Tetralogy & 4 & 2.44 \\
\hline & Levocardia & 4 & 2.44 \\
\hline & Non specified Liver Insufficiency & 3 & 1.83 \\
\hline & Others group 1 Non-Oncological & 22 & 13.41 \\
\hline \multirow[t]{5}{*}{2} & Specified neuromuscular diseases & 11 & 28.95 \\
\hline & $\begin{array}{l}\text { Cystic Fibrosis with/without extra pulmonary } \\
\text { manifestations }\end{array}$ & 9 & 23.68 \\
\hline & $\begin{array}{l}\text { Congenital Absence, atresia and stenosis of } \\
\text { digestive organs }\end{array}$ & 9 & 23.68 \\
\hline & $\begin{array}{l}\text { Osteochondrodysplasia and Osteogenesis } \\
\text { Imperfecta }\end{array}$ & 6 & 15.79 \\
\hline & Kidney Dysplasia & 3 & 7.89 \\
\hline \multirow[t]{10}{*}{3} & Myoclonus & 11 & 26.19 \\
\hline & Extrapyramidal and motion disorders & 9 & 21.43 \\
\hline & Demyelinating diseases & 4 & 9.52 \\
\hline & Non specified Dystonia & 4 & 9.52 \\
\hline & Degenerative Diseases & 3 & 7.14 \\
\hline & Diffuse Sclerosis & 2 & 4.76 \\
\hline & Other Choreas & 2 & 4.76 \\
\hline & Motor Neurons Diseases & 2 & 4.76 \\
\hline & $\begin{array}{l}\text { Other Spinal Muscular Atrophies and related } \\
\text { syndromes }\end{array}$ & 2 & 4.76 \\
\hline & Others Group 3 & 3 & 7.14 \\
\hline \multirow[t]{12}{*}{4} & Epilepsies & 284 & 72.26 \\
\hline & Quadriplegic Spastic cerebral palsy & 27 & 6.87 \\
\hline & Hydrocephalus & 13 & 3.31 \\
\hline & Family Dysautonomia [Riley-Day Syndrome] & 13 & 3.31 \\
\hline & Spinal Cord disorders & 9 & 2.29 \\
\hline & $\begin{array}{l}\text { Central Nervous system disorders and cerebral } \\
\text { injury }\end{array}$ & 9 & 2.29 \\
\hline & Non specified Encephalopathy & 7 & 1.78 \\
\hline & Benign intracranial Hypertension & 7 & 1.78 \\
\hline & Cerebral Cyst & 7 & 1.78 \\
\hline & Hemiplegia and Monoplegia & 5 & 1.27 \\
\hline & Cerebral Edema & 3 & 0.76 \\
\hline & Others Group 4 & 9 & 2.29 \\
\hline \multirow[t]{4}{*}{5} & Others preterm newborns & 767 & 81.51 \\
\hline & Other Low Birth weight & 62 & 6.59 \\
\hline & Neonatal Cerebral Depression & 24 & 2.55 \\
\hline & Asphyxiation of birth & 22 & 2.34 \\
\hline
\end{tabular}




\begin{tabular}{|l|l|r|r|}
\hline \hline & Congenital Hypotonia & 18 & 1.91 \\
\hline & Extreme Immaturity & 17 & 1.81 \\
\hline Cerebral Malformations & 9 & 0.96 \\
\hline Extreme Low Birth Weight & 5 & 0.53 \\
\hline Non specified Intrauterine Hypoxia & 4 & 0.43 \\
\hline & Cerebral Hemorrhage & 2 & 0.21 \\
\hline Others Group 5 & 11 & 1.17 \\
\hline
\end{tabular}


Figures

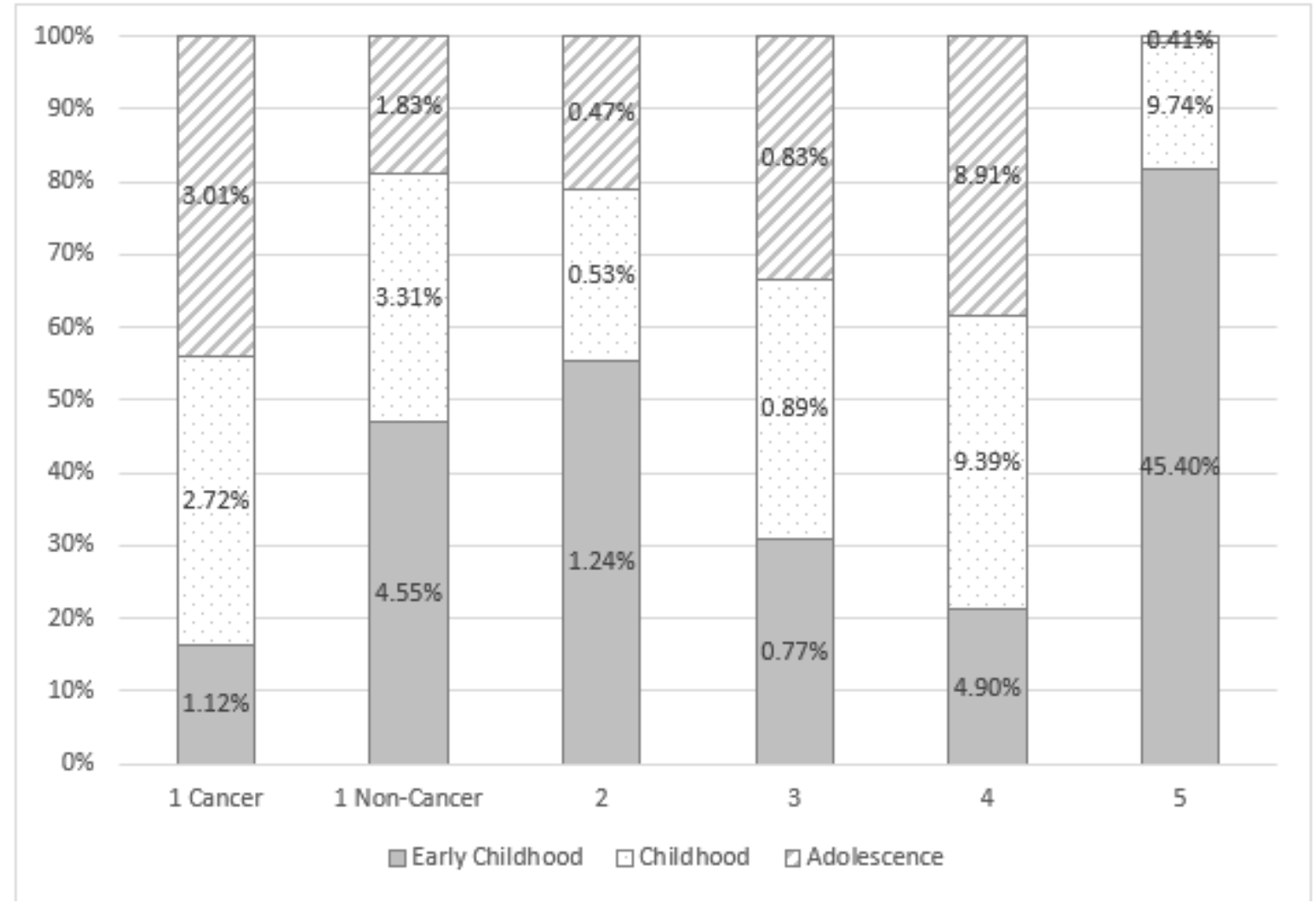

Figure 1

Distribution of diagnoses by age group and ACT group classifications plus group 5. Seguros Sura Insurance Company, Colombia 2016-2018. 